\title{
Ventral Pallidum Output Pathways in Context-Induced Reinstatement of Alcohol Seeking
}

\author{
(1)Asheeta A. Prasad and Gavan P. McNally \\ School of Psychology, University of New South Wales, Sydney, 2052 NSW, Australia
}

Ventral pallidum (VP) is a well-established locus for the reinforcing effects of drugs of abuse and reinstatement of drug seeking. However, VP neurons are at the origin of multiple output pathways, with strong projections to ventral tegmental area (VTA), subthalamic nucleus (STN), lateral hypothalamus, among others, and the roles of these VP output pathways in reinstatement of drug seeking remain poorly understood. Here we addressed these issues using a combination of neuroanatomical tracing and chemogenetic approaches. First, using dual-retrograde tracing, we show that VP neurons projecting to either VTA or STN are recruited during context-induced reinstatement of extinguished alcohol seeking in rats. Then, using chemogenetics, we show modulation of context-induced reinstatement and reacquisition of alcohol seeking via designer receptors exclusively activated by designer drugs excitation or inhibition of the VP. To determine the causal roles of VP $\rightarrow$ VTA and VP $\rightarrow$ STN pathways in context-induced reinstatement and reacquisition we used a chemogenetic disconnection approach and show that silencing either the VP $\rightarrow$ VTA or VP $\rightarrow$ STN pathways is sufficient to reduce both reinstatement and reacquisition of alcohol seeking. Moreover, these disconnections also each reduced responding and motivation during a progressive ratio test but had no effect on locomotor activity. Together, these results show that multiple ventral pallidal output pathways contribute to relapse to alcohol seeking.

Key words: DREADD; reinstatement; relapse; ventral pallidum

Significance Statement

Ventral pallidum (VP) serves important roles in reward and motivation and is a critical node in the neural circuitry for reinstatement of drug seeking. Despite being a common locus for different forms of reinstatement, fundamental aspects of neural circuitry for these VP contributions to reinstatement of drug seeking remain unknown. Here we used a combination of neuroanatomical tracing and chemogenetic approaches to map the VP output pathways for context-induced reinstatement and reacquisition of alcohol seeking. We show that VP output pathways to the subthalamic nucleus and also to the ventral tegmental area are necessary for these forms of reinstatement.

\section{Introduction}

The ventral pallidum (VP), a major basal ganglia output structure (Heimer et al., 1982; Zahm et al., 1987, 1996; Zahm and Heimer, 1990), serves a critical role in reward and motivation (Smith et al., 2009; Root et al., 2015; Richard et al., 2016). VP is a well-established locus for the reinforcing effects of drugs of abuse and reinstatement of drug seeking. For example, microinjections of mu opioid receptor antagonists (Tang et al., 2005; Perry and

\footnotetext{
Received Aug. 14, 2016; revised Sept. 24, 2016; accepted Sept. 26, 2016.

Author contributions: A.A.P. and G.P.M. designed research; A.A.P. performed research; A.A.P. and G.P.M. analyzed data; A.A.P. and G.P.M. wrote the paper.

This work was supported by National Health and Medical Research Council Grants 1047899 and 1098436 and Australian Research Council Future Fellowship FT120100250 to G.P.M.

The authors declare no competing financial interests.

Correspondence should be addressed to Dr. Gavan P. McNally, School of Psychology, University of New South

Wales, Sydney, 2052 NSW, Australia. E-mail: g.mcnally@unsw.edu.au.

DOI:10.1523/JNEUROSCI.2580-16.2016

Copyright $\odot 2016$ the authors $\quad 0270-6474 / 16 / 3611716-11 \$ 15.00 / 0$
}

McNally, 2013), pharmacological inactivation (McFarland and Kalivas, 2001; McFarland et al., 2004), or chemogenetic silencing (Mahler et al., 2014) of VP prevent a variety of forms of reinstatement to drug seeking. Multiple striatal, cortical, and amygdala inputs converge on VP during reinstatement (Perry and McNally, 2013), with projections from nucleus accumbens core (AcbC) especially important. Pharmacological disconnection of dorsal medial prefrontal cortex and VP (McFarland and Kalivas, 2001) or optogenetic silencing of the AcbC $\rightarrow$ VP pathway prevents reinstatement of cocaine or reacquisition of alcohol seeking (Stefanik et al., 2013; Khoo et al., 2015). These findings support VP as a key component of a cortical-striatal-pallidal pathway for reinstatement of drug seeking (Kalivas and Volkow, 2005, 2011).

However, fundamental aspects of VP contributions to reinstatement of drug seeking remain poorly understood. Of relevance here, little is known regarding the critical VP outputs for reinstatement. Mahler et al. (2014) identified a role for the VP $\rightarrow$ 
ventral tegmental area (VTA) projection in reinstatement of cocaine seeking in rats. VP neurons projecting to VTA (ventromedial VP or "rostral" VP) were recruited during cue-induced reinstatement of cocaine seeking and chemogenetic silencing of VP terminals in VTA or disconnection of VP from VTA dopamine neurons prevented this reinstatement. However, the role of the VP $\rightarrow$ VTA pathway in reinstatement to seeking other drugs is unknown. It is also unknown whether this role is unique to the $\mathrm{VP} \rightarrow$ VTA pathway or whether it is shared with VP efferents to thalamus, hypothalamus, and midbrain. For example, ventromedial VP projects to VTA but also lateral hypothalamus (Zahm, 1989; Groenewegen et al., 1993; Zahm et al., 1996; Tripathi et al., 2013), a region strongly implicated in reinstatement of drug seeking (Marchant et al., 2009, 2012, 2014), whereas dorsolateral VP projects extensively to subthalamic nucleus (STN) and substantia nigra (Zahm, 1989; Groenewegen et al., 1993; Zahm et al., 1996; Tripathi et al., 2013). VP projections to STN are of considerable interest because STN manipulations reduce motivation for cocaine as well as alcohol (Baunez et al., 2005; Lardeux and Baunez, 2008; Rouaud et al., 2010) and reduce reinstatement of methamphetamine seeking (Baracz et al., 2015), but it is unknown whether this role for STN in motivation and reinstatement of drug seeking is linked to its VP inputs.

Here we addressed these issues using a combination of neuroanatomical tracing and chemogenetic approaches. First, using dual-retrograde tracing, we asked whether VP neurons projecting to VTA or STN were recruited during context-induced reinstatement (ABA renewal) (Crombag and Shaham, 2002; Hamlin et al., 2007; Bouton and Todd, 2014) of alcohol seeking in rats. Then, using chemogenetics, we asked whether modulation of VP or VP $\rightarrow$ VTA and VP $\rightarrow$ STN pathways affected context-induced reinstatement and reacquisition of alcohol seeking.

\section{Materials and Methods}

Subjects. Subjects were experimentally naive male Sprague Dawley rats (300-350 g), obtained from the Animal Resources Centre. Rats were housed in groups of four in ventilated racks maintained in a climatecontrolled colony room. The colony room was maintained on a $12 \mathrm{~h}$ light/dark cycle (lights on 7:00 A.M.). Experiments were conducted during the light cycle. Food and water were available ad libitum until $2 \mathrm{~d}$ before behavioral training, after which rats were allowed $1 \mathrm{~h}$ access to food and water following daily training sessions. The University of New South Wales Animal Care and Ethics Committee approved the procedures.

Apparatus. Training, extinction, and test were conducted in standard operant chambers (Med Associates), enclosed in sound-and lightattenuating cabinets equipped with fans providing constant ventilation and low-level background noise. Inside each chamber were two nosepokes containing a white cue-light and a recessed magazine. Responding on one (active) nosepoke delivered $4 \%$ (v/v) decarbonated alcoholic beer to the magazine, whereas responding on the other (inactive) nosepoke had no consequences. For experiments that involved manipulation of context, these chambers were arranged in two sets of four that differed in their visual (illuminated by an overhead LED vs dark), tactile (Perspex vs grid floors), and olfactory (rose oil vs peppermint essence) properties, as described previously. The two sets of chambers were fully counterbalanced to serve as contexts A and B.

Locomotor activity was assessed in Plexiglas chambers (Med Associates) $43.2 \mathrm{~cm}$ (width) $\times 43.2 \mathrm{~cm}$ (length) $\times 30.5 \mathrm{~cm}$ (height) for $40 \mathrm{~min}$. Movement was tracked through the use of three 16 beam infrared arrays. Infrared beams were located on both the $x$ - and $y$-axes for positional tracking.

Viral vectors and retrograde tracers. Adeno-associated viral vectors encoding the hM3Dq or hM4Di designer receptors exclusively activated by designer drugs (DREADDs) (Urban and Roth, 2015; Roth, 2016) or eYFP were obtained from University of North Carolina Vector Core (Chapel
Hill, NC). The vectors used in these experiments were AAV5-hSyn-HAhM3D $\mathrm{q}_{\mathrm{q}}$-IRES-mCitrine $\left(2 \times 10^{12} \mathrm{vp} / \mathrm{ml}\right)$, AAV5-hSyn-HA-hM4D $\mathrm{i}^{-}$ IRES-mCitrine $\left(2 \times 10^{-2} \mathrm{vp} / \mathrm{ml}\right)$, and AAV5-hSyn-eYFP $(4 \times$ $10^{12} \mathrm{vp} / \mathrm{ml}$ ). The retrograde tracers were cholera toxin $\mathrm{b}$ subunit $(\mathrm{CTb})$ conjugated to AlexaFluor-488 (CTb-488) or AlexaFluor-555 (CTb-555) (ThermoFisher Scientific). CNO was obtained from the RTI International. CNO was dissolved in 5\% DMSO (Sigma) and 0.9\% sterile saline solution.

Surgery. Before surgery, rats received an intraperitoneal injection of a mixture of $100 \mathrm{mg} / \mathrm{ml}$ ketamine (Ketapex, Apex Laboratories) and $0.3 \mathrm{ml} / \mathrm{kg}$ xylazine (Rompun; Bayer) and an injection of the antiinflammatory carprofen (Rimadyl, $3 \mathrm{mg} / \mathrm{kg}$ ). Once anesthetized, rats were placed in a stereotaxic apparatus (model 942, Kopf) and shaved to expose the skin surface of the head. Before incision, rats received a subcutaneous injection of carprofen $(5 \mathrm{mg} / \mathrm{kg})$ and an injection of $0.5 \%$ bupivacaine (Cenvet) just under the surface of incision site. Following incision, a hand drill was used to make craniotomies above the target region and a $5 \mu \mathrm{l}, 30$-gauge conical tipped microinfusion syringe (Hamilton) was used to infuse $0.75 \mu \mathrm{l}$ of AAV vectors into VP $(-0.12 \mathrm{AP}, \pm 2.5$ $\mathrm{ML},-8.4 \mathrm{DV}), 0.50 \mu \mathrm{l}$ into STN $(-3.6 \mathrm{AP}, \pm 2.5 \mathrm{ML},-8.8 \mathrm{DV})$, and $0.75 \mu$ l into VTA $(-5.6 \mathrm{AP}, \pm 2.25$ [10-degree angle] ML, $-8.3 \mathrm{DV})$ over a $3 \mathrm{~min}$ period at a rate of $0.25 \mu \mathrm{l} / \mathrm{min}$ (UMP3 with SYS4 Microcontroller; World Precision Instruments). The syringe was left in place for 5-7 min to permit diffusion of the injected vectors. CTb-488 and CTb$555(0.1 \mu \mathrm{l})$ were infused unilaterally into the VTA $(-5.6 \mathrm{AP}, \pm 2.25$ [10-degree angle] ML, $-8.3 \mathrm{DV})$ and contralateral STN ( $-3.6 \mathrm{AP}, \pm 2.5$ $\mathrm{ML},-8.8 \mathrm{DV}$ ) (counterbalanced across hemispheres) using a 30 gauge conical tipped microinfusion syringe at a rate of $0.5 \mu \mathrm{l} / \mathrm{min}$ (UMP3 with SYS4 Microcontroller; World Precision Instruments). All stereotaxic coordinates are distances in millimeters from bregma (Paxinos and Watson, 2007). Bone wax (Coherent Scientific) was used to seal the opening of the skull. After surgery, rats were injected intraperitoneally with $0.3 \mathrm{ml}$ of $300 \mathrm{mg} / \mathrm{ml}$ solution of procaine penicillin (Benicillin; Illium) and subcutaneously with $0.3 \mathrm{ml}$ of a $100 \mathrm{mg} / \mathrm{ml}$ solution of cephazolin (Hospira). Daily postoperative and recovery procedures, including weight and infection management, were conducted for the remainder of the experiment. All behavioral procedures commenced a minimum of 2 weeks after surgery.

Behavioral testing procedures. On the first $2 \mathrm{~d}$, the animals received 20 min magazine training sessions in both chambers. During these sessions, there were 10 noncontingent deliveries of $0.6 \mathrm{ml}$ of the reward $(4 \%$ alcohol $\mathrm{v} / \mathrm{v}$ decarbonated beer) at time intervals variable around a mean of $1.2 \mathrm{~min}$. On the next 10 days, rats received self-administration training, in context $\mathrm{A}$ for $1 \mathrm{~h}$ per day. During this time, responding on the active nosepoke extinguished the nosepoke cue light and triggered delivery of $0.6 \mathrm{ml}$ of beer to the magazine on an FR-1 schedule followed by a $24 \mathrm{~s}$ timeout. Responses on the inactive nosepoke were recorded but had no programmable consequences. On the next $4 \mathrm{~d}$, rats received extinction training, in context $\mathrm{B}$ for $\mathrm{h}$ per day. During this training, responses on the active nosepoke extinguished the cue light and triggered the pump, but no beer was delivered. All rats were tested starting $24 \mathrm{~h}$ after the last extinction session. A minimum of $24 \mathrm{~h}$ separated each test. These parameters were chosen based on our past research, which shows robust acquisition, extinction, and renewal of responding under these conditions (Hamlin et al., 2006, 2007, 2008).

Experiment 1: VP output pathways recruited during context-induced reinstatement of alcohol seeking. To assess recruitment of the VP $\rightarrow$ VTA and VP $\rightarrow$ STN pathways during context-induced reinstatement, we applied the retrograde tracers CTb-488 and CTb-555 (counterbalanced) to one VTA and to the contralateral STN. There were three groups: Group $\mathrm{ABB}(n=8)$, Group $\mathrm{ABA}(n=8)$, and Group $\mathrm{AB} 0(n=8)$. All rats were trained to respond for alcoholic beer in context $A$ and extinguished in context B. Rats were tested once, for $1 \mathrm{~h}, 24 \mathrm{~h}$ after the last extinction session. Group ABB was tested in the extinction context. Group ABA was tested in the training context. Group $\mathrm{AB} 0$ was not tested; instead, they were simply transported to the laboratory on test and received an equivalent period of handling. This group served as a control for the behavioral and pharmacological training histories. All rats were perfused $1 \mathrm{~h}$ after 
test (or at the equivalent time for Group AB0). Their brains were later processed for expression of the c-Fos protein and the CTb tracers.

Experiment 2: VP chemogenetic manipulation on context-induced reinstatement and reacquisition of alcohol seeking. In Experiment 2a, there were two groups, eYFP $(n=7)$ and hM4Di $(n=7)$, which refer to the AAV vector expressed in the VP. In Experiment $2 b$, there were two groups, eYFP $(n=7)$ and hM3Dq $(n=6)$, which refer to the AAV vector expressed in the VP. These experiments were run at different times. In both experiments, rats were trained and extinguished as described above. In both experiments, testing commenced $24 \mathrm{~h}$ after extinction. Rats were tested for $1 \mathrm{~h}$ in the extinction context $(\mathrm{ABB})$ and for $1 \mathrm{~h}$ in the training context (ABA) for expression of extinction and renewal (contextinduced reinstatement), respectively. These tests were separated by $24 \mathrm{~h}$, and the order of tests was counterbalanced within subjects. Rats were tested $24 \mathrm{~h}$ later for $1 \mathrm{~h}$ reacquisition of alcoholic beer seeking in the training context. Our past research has shown no impact of the prior order of $\mathrm{ABA}$ and $\mathrm{ABB}$ testing on responding during reacquisition. Rats received a single intraperitoneal injection of $\mathrm{CNO} 90 \mathrm{~min}$ before each of these tests, which is consistent with the pharmacokinetics of $\mathrm{CNO}$ and studies showing long-lasting behavioral and electrophysiological effects (Urban and Roth, 2015; Roth, 2016). For Experiments 2a and 3, the dose of CNO was $20 \mathrm{mg} / \mathrm{kg}$ (Mahler et al., 2014); whereas for Experiment 2b, it was $3 \mathrm{mg} / \mathrm{kg}$ (Yau and McNally, 2015; Sengupta et al., 2016).

Experiment 3: Chemogenetic disconnection of the VP $\rightarrow$ VTA and $V P \rightarrow S T N$ pathways on context-induced reinstatement and reacquisition of alcohol seeking. There were three groups: ipsilateral, VP $\rightarrow$ VTA disconnection, and VP $\rightarrow$ STN disconnection. The ipsilateral group $(n=$ 12) received hM4Di applied to the VP in one hemisphere (counterbalanced across the left and right hemispheres) and also hM4Di applied to the ipsilateral VTA $(n=6)$ or the ipsilateral STN $(n=6)$. The VP $\rightarrow$ VTA disconnection group $(n=8)$ received hM4Di applied to the VP in one hemisphere (counterbalanced across the left and right hemispheres) and also hM4Di applied to the contralateral VTA. The VP $\rightarrow$ STN disconnection group $(n=8)$ received hM4Di applied to the VP in one hemisphere (counterbalanced across the left and right hemispheres) and also hM4Di applied to the contralateral STN. All rats were then trained, extinguished, and tested for expression of extinction (ABB), context-induced reinstatement (ABA), and reacquisition as per Experiment 2.

After reacquisition test, rats rested for $2 \mathrm{~d}$ in their home cage. Then they received a single session of retraining, identical to self-administration, to ensure that all groups reached similar levels of responding. Rats were tested the following day in a progressive ratio (PR) test. During these tests, active nosepokes were rewarded on a PR schedule. The schedule was derived from the function where response ratio equals to $\left[5^{\text {e(reinforcer number } \times 0.2)}\right]-5$, rounded to the nearest integer (Richardson and Roberts, 1996). The next day, rats were placed in locomotor chambers for $30 \mathrm{~min}$ to habituate them to the chambers. Finally, $24 \mathrm{~h}$ later, they were tested for locomotor activity for $30 \mathrm{~min}$. Rats received an intraperitoneal injection of CNO $(20 \mathrm{mg} / \mathrm{kg})$ (Mahler et al., 2014) 90 min before ABB, ABA, PR, and locomotor tests.

Immunohistochemistry. At the conclusion of the experiments, rats were deeply anesthetized with sodium pentobarbital (100 mg/kg, i.p.) and perfused transcardially with $150 \mathrm{ml}$ of $0.9 \%$ saline, containing heparin (5000 $\mathrm{IU} / \mathrm{ml}$ ), followed by $400 \mathrm{ml}$ of $4 \%$ PFA in $0.1 \mathrm{M}$ phosphate buffer (PB), $\mathrm{pH}$ 7.4. Brains were postfixed for $1 \mathrm{~h}$ in the same fixative and placed in $20 \%$ sucrose solution overnight. Brains were frozen and sliced to $40 \mu \mathrm{m}$ coronal sections. Four serially adjacent sets from the VP were obtained from each brain and stored in $0.1 \%$ sodium azide in $0.1 \mathrm{M}$ PBS, pH 7.2.

Immunoreactivity for mCitrine (AAV5-hSyn-eYFP, AAV5-hSyn-HAhM3Dq-IRES-mCitrine, AAV5-hSyn-HA-hM4Di-IRES-mCitrine) was performed using an eGFP antibody. Sections were washed in $0.1 \mathrm{M} \mathrm{PB}$, followed by $50 \%$ ethanol, $50 \%$ ethanol with $3 \%$ hydrogen peroxidase, then 5\% normal horse serum in PB (30 min each). Sections were then incubated in rabbit antiserum against eGFP (1:2000; Invitrogen, catalog \#AA11122) in a PB solution blocking buffer (2\% normal horse serum and $0.2 \%$ Triton $\mathrm{X}-10)\left(48 \mathrm{~h}\right.$ at $\left.4^{\circ} \mathrm{C}\right)$. The sections were then washed and incubated in biotinylated donkey anti-rabbit (1:1000; catalog $\# 11,065,152$, Jackson ImmunoResearch Laboratories, $24 \mathrm{~h}$ at $\left.4^{\circ} \mathrm{C}\right)$. Finally, the sections were incubated in avidin-biotinylated HRP complex (Vector Elite kit: $6 \mu \mathrm{l} / \mathrm{ml}$ avidin and $6 \mu \mathrm{l} / \mathrm{ml}$ biotin; Vector Laboratories,
$2 \mathrm{~h}$ at room temperature), washed in $\mathrm{PB}$, and then incubated ( $15 \mathrm{~min})$ in a DAB solution containing $0.1 \%$ 3,3-diaminobenzidine, $0.8 \%$ D-glucose and $0.016 \%$ ammonium chloride. Immunoreactivity was catalyzed by the addition of $0.2 \mu \mathrm{l} / \mathrm{ml}$ glucose oxidase $(24 \mathrm{mg} / \mathrm{ml}, 307 \mathrm{U} / \mathrm{mg}$, SigmaAldrich). Brain sections were then washed in $\mathrm{PB}, \mathrm{pH}$ 7.4.

For detection of c-Fos (Experiment 1 only), brain sections were then incubated in rabbit anti-c-Fos (1:500, sc52; Santa Cruz Biotechnology) for $24 \mathrm{~h}$ at $4^{\circ} \mathrm{C}$. The primary antibodies were diluted in blocking buffer. After washing off unbound primary antibody, sections were incubated overnight at $4^{\circ} \mathrm{C}$ in biotinylated donkey anti-rabbit IgG (1:500; catalog \#711065152, Jackson ImmunoResearch Laboratories) diluted in blocking buffer. After washing off unbound secondary antibody, sections were incubated for overnight at $4^{\circ} \mathrm{C}$ in streptavidin, AlexaFluor-350 conjugate (1:300, S11249, Invitrogen). Brain sections were then washed in $\mathrm{PB}, \mathrm{pH}$ 7.4, and mounted using mounting media. VP sections were delineated according to Paxinos and Watson (2007) and imaged at $20 \times$ using a transmitted light microscope (Olympus BX51). Counts of all neurons immunoreactive (IR) for c-Fos and CTb-488 or CTb-555 native fluorescence across $3 \mathrm{VP}$ sections ( $80 \mu \mathrm{m}$ apart) were made using Photoshop (Adobe).

Data analyses. The numbers of nosepokes were recorded during training, extinction, and tests. For locomotor activity, the number and location of beam breaks were counted. These data, as well as the total counts of c-Fos-IR, CTb, and c-Fos-IR/CTb neurons in VP, were analyzed by means of planned contrasting testing procedure. A multivariate approach to repeated measures was adopted (Boik, 2016). The Type I error rate $(\alpha)$ was controlled at 0.05 for each contrast tested (Harris, 2004).

\section{Results}

Experiment 1: VP output pathways recruited during contextinduced reinstatement of alcohol seeking

First, we examined recruitment of VP projections to the VTA and STN during context-induced reinstatement of alcohol seeking. Rats with CTb-488 and CTb-555 applied to one VTA and the contralateral STN were trained to respond for alcoholic beer in one context (A) before extinction in a second context. One group $(\mathrm{AB} 0)$ remained in their home cage on test and received handling. A second group $(\mathrm{ABB})$ was tested in the extinction context. The third group $(\mathrm{ABA})$ was tested in the training context. We examined recruitment of the VP $\rightarrow$ VTA and VP $\rightarrow$ STN pathways during these tests by assessing expression of the c-Fos protein in the VP and its colocalization with CTb-488 and CTb-555.

\section{Histology}

Four animals were excluded due to incorrect placement of $\mathrm{CTb}$ outside the boundaries of the STN or VTA. Some animals (ABA, $n=1 ; \mathrm{ABB}, n=2 ; \mathrm{AB} 0, n=1)$ had correct $\mathrm{CTb}$ placement in one region but not the other. These animals were included in analyses for the correct $\mathrm{CTb}$ placement but excluded for the incorrect $\mathrm{CTb}$ placement.

\section{Behavior}

All rats acquired alcohol self-administration. Averaged across the last $3 \mathrm{~d}$ of acquisition training, the mean \pm SEM nosepokes for $\mathrm{ABA}$ were $99.67 \pm 12.26$ (active) and $1.57 \pm 0.81$ (inactive), $\mathrm{ABB}$ were $105.43 \pm 12.23$ (active) and $1.38 \pm 0.20$ (inactive), and for $\mathrm{AB} 0$ were $107.50 \pm 17.00$ (active) and $1.72 \pm 0.58$ (inactive). There were significantly more active than inactive nosepokes $\left(F_{(1,17)}=165.95, p<0.05\right)$ but no overall difference between AB0 and $\mathrm{ABB}, \mathrm{ABA}\left(F_{(1,17)}=0.09, p>0.05\right)$ groups. During extinction training (Fig. $1 A$ ), rats made significantly more active than inactive nosepokes $\left(F_{(1,17)}=113.56, p<0.05\right)$. Responding decreased across days of extinction $\left(F_{(1,17)}=61.48, p<0.05\right)$. This decrease was greater for the active than the inactive nosepoke $\left(F_{(1,17)}=77.96, p<0.05\right)$. However, there were no interactions 
A
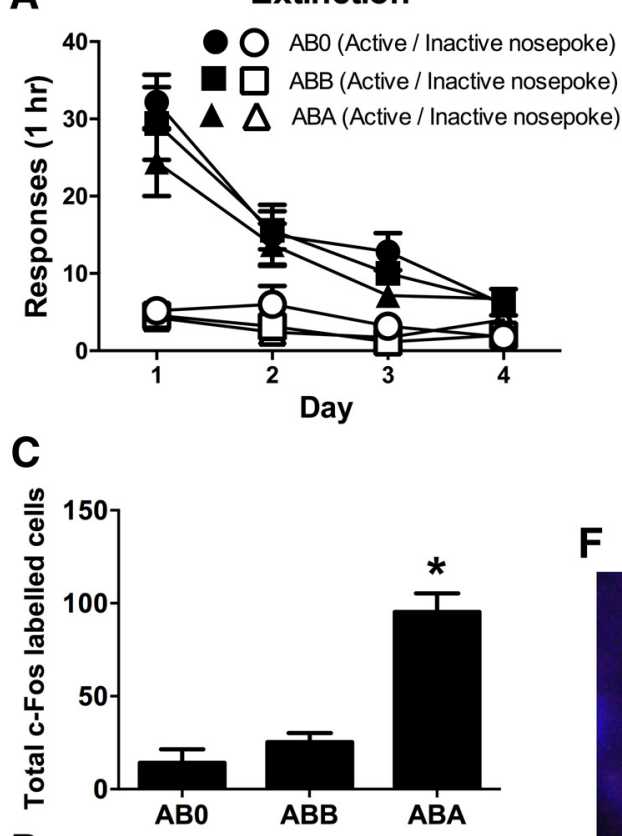

D

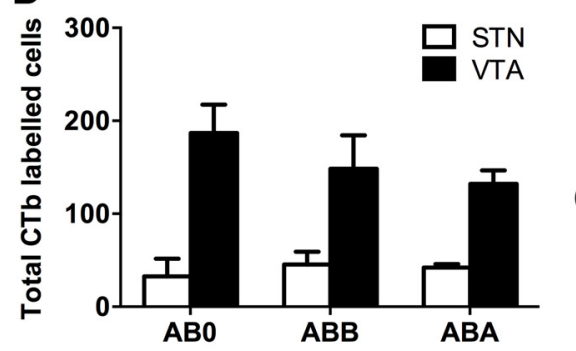

E

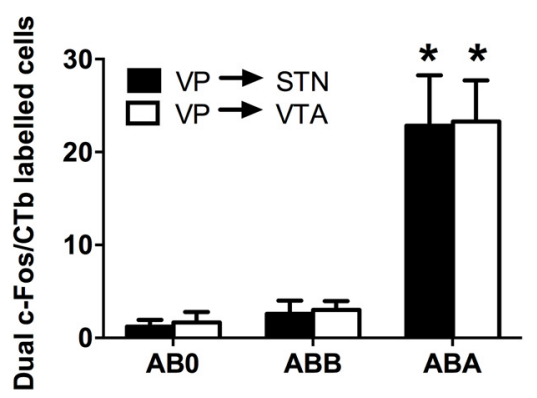

$\mathbf{F}$

G
B

Test
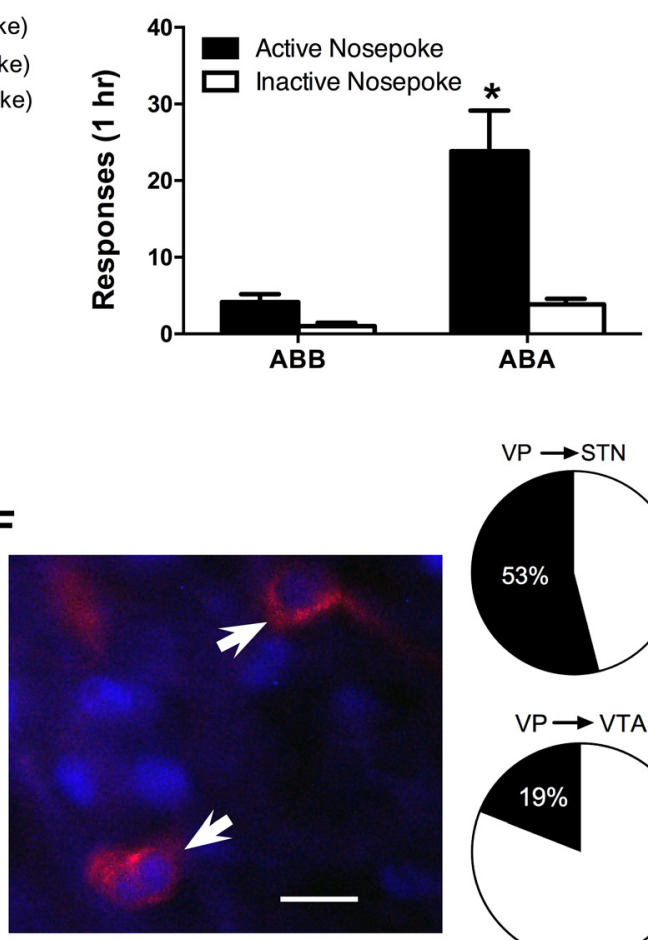

$\mathrm{VP} \rightarrow \mathrm{STN}$

$53 \%$

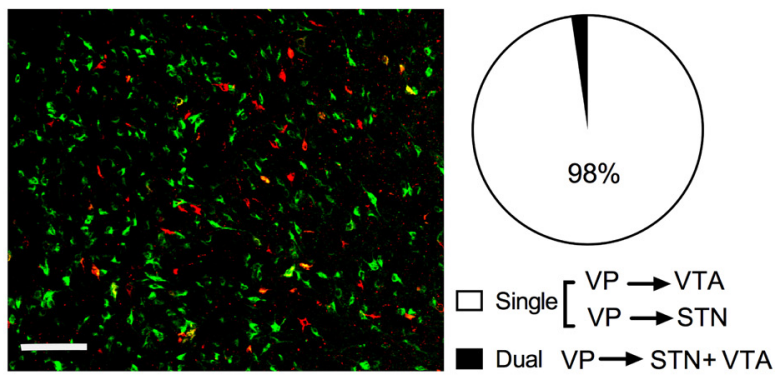

Figure 1. $A$, Mean ( \pm SEM) responding during extinction training. $B$, Mean ( \pm SEM) responding during test. There was context-induced reinstatement of alcohol seeking when animals were tested in the training (ABA) context. C, Mean ( \pm SEM) counts of $\mathrm{C}$-Fos-IR in VP during expression of context-induced reinstatement ( $A B A, n=7)$, extinction ( $A B B, n=7)$, or in controls trained and extinguished but never tested $(A B O, n=6)$. There was reinstatement-associated c-Fos in Group ABA. D, Mean ( \pm SEM) counts of VP neurons retrogradely labeled from either VTA or STN. There were no differences between Groups $A B A, A B B$, and $A B 0$ in number of retrograde-labeled neurons. $E$, Mean ( $\pm S E M$ ) counts of dual c-Fos/CTb-labeled VP neurons, with significantly more dual-labeled VP neurons from either STN or VTA in Group ABA. $\boldsymbol{F}$, Example of dual-labeled VP neuron (blue represents c-Fos; red represents (Tb), and proportion of retrograde-labeled VP neurons expressing c-Fos for each pathway. G, Example of segregation of VP neurons projecting to the STN (red) or VTA (green) and proportion of labeled neurons projecting to either STN or VTA (single) versus projecting to both STN and VTA (dual). ${ }^{*} p<0.05$, compared with $A B B(B)$ or ABB and ABO (C,E). Scale bars: $\boldsymbol{F}, 31.25 \mu \mathrm{m} ; \boldsymbol{G}, 125 \mu \mathrm{m}$.

between extinction and any of the differences between groups $\left(F_{(1,17)}=1.02, p>0.05\right)$.

On test (Fig. $1 B$ ), there was more active than inactive responding $\left(F_{(1,12)}=17.81, p<0.05\right)$. There was overall more responding in the training context $(\mathrm{ABA})$ compared with the extinction context $(\mathrm{ABB})\left(F_{(1,12)}=17.22, p<0.05\right)$, and this increase in responding upon test in the training context was greater for the active compared with the inactive nosepoke $\left(F_{(1,12)}=17.81, p<0.05\right)$. Hence, there was evidence for context-induced reinstatement.
Immunohistochemistry

Context-induced reinstatement was associated with significant c-Fos-IR in the VP (Perry and McNally, 2013). Group ABA expressed significantly more c-Fos-IR than Groups ABB and AB0 $\left(F_{(1,17)}=64.60 ; p<0.05\right)$, which did not differ from each other $\left(F_{(1,17)}<1 ; p>0.05\right)$ (Fig. $\left.1 C\right)$. There were no significant differences between groups in the number of VP neurons retrogradely labeled from VTA $\left(F_{(1,17)}<1 ; p>0.05\right)$ or STN $\left(F_{(1,13)}<1 ; p>\right.$ 0.05 ) (Fig. $1 D$ ). For both the VP $\rightarrow$ STN and VP $\rightarrow$ VTA projections, there were significantly more dual-labeled c-Fos-IR/CTb 
neurons (Fig. $1 E, F$ ) in Group ABA compared with Groups $\mathrm{ABB}$ and $\operatorname{AB} 0 \operatorname{VTA}\left(F_{(1,17)}=37.53, p<0.05\right)$ and $\operatorname{STN}\left(F_{(1,13)}=\right.$ 165.67, $p<0.05$ ) (Fig. $1 D$ ), and Groups ABB and AB0 did not differ from each other (VTA: $F_{(1,17)}<1, p>0.05$; $\operatorname{STN} F_{(1,13)}<$ $1, p>0.05)$. A total of $53 \%$ of VP neurons retrograde-labeled from STN, and 19\% of VP neurons retrograde-labeled from VTA, expressed c-Fos-IR during context-induced reinstatement (Fig. $1 F$ ). So, context-induced reinstatement was associated with recruitment of the VP $\rightarrow$ VTA and VP $\rightarrow$ STN pathways.

Our procedure did not allow examination of the extent of colocalization of the VP $\rightarrow$ VTA and VP $\rightarrow$ STN pathways because each tracer was applied to a different hemisphere. So, in a separate group $(n=10)$, we applied CTb-488 and CTb-555 to one VTA and the ipsilateral STN. We examined VP for colabeled neurons indicative of the same VP neurons at the origins of the VP $\rightarrow$ VTA and VP $\rightarrow$ STN pathways. Consistent with past reports that the $\mathrm{VP} \rightarrow \mathrm{STN}$ and $\mathrm{VP} \rightarrow \mathrm{VTA}$ pathways are segregated with distinct topographical organization (Zahm, 1989; Zahm and Heimer, 1990; Groenewegen et al., 1993), we saw little colocalization of the two tracers in VP neurons retrogradely labeled from these two sites (Fig. 1G). Approximately $98 \%$ of labeled neurons were retrograde-labeled from either the VTA or STN, and only $\sim 2 \%$ of neurons retrograde-labeled from both. Consistent with past research, STN-projecting VP neurons tended to be located in dorsolateral portions of the VP, whereas VTA-projecting neurons tended to be located in ventromedial medial portions; however, there was considerable intermingling of these populations.

\section{Experiment 2: effects of chemogenetic inhibition or excitation of VP neurons on context-induced reinstatement and reacquisition of extinguished alcohol seeking}

Having established recruitment of key VP output pathways during context-induced reinstatement, we next examined the effects of chemogenetic inhibition or excitation of VP neurons on reinstatement of extinguished alcohol seeking. In separate experiments, we expressed the inhibitory hM4Di DREADD or eYFP (Experiment 2a) or the excitatory hM3Dq DREADD or eYFP (Experiment $2 \mathrm{~b}$ ) in VP neurons. We trained and extinguished animals, then tested for expression of extinction $(\mathrm{ABB})$, contextinduced reinstatement (ABA), and reacquisition of alcoholseeking. We used two different forms of reinstatement (context and reacquisition) because they model different features of relapse. Whereas context-induced reinstatement, such as cue- and stress-induced reinstatement, assesses reinstatement in the absence of the reinforcer, reacquisition uniquely models features of relapse that depend on contingent contact with the reinforcer. Reacquisition and context-induced reinstatement depend on different inputs to VP (Khoo et al., 2015), and it remains to be determined whether they share common VP substrates or output pathways.

\section{hM4Di histology}

Figure $2 A$ shows the maximal extent of eYFP-IR across all rats included in the analyses, with each rat represented at $20 \%$ opacity. One rat was excluded because of unilateral expression of hM4Di.

\section{hM4Di behavior}

All rats acquired self-administration. Averaged across the last $3 \mathrm{~d}$ of acquisition training, the mean \pm SEM nosepokes for eYFP were $151.14 \pm 26.83$ (active) and $2.14 \pm 0.39$ (inactive) and for hM4Di were $117.95 \pm 1.67$ (active) and $11.07 \pm 0.51$ (inactive). There were significantly more active than inactive nosepokes
$\left(F_{(1,12)}=83.05, p<0.05\right)$ but no overall difference between eYFP and hM4Di $\left(F_{(1,12)}<1.35, p>0.05\right)$ groups. During extinction training (Fig. $2 B$, inset), all rats made significantly more active than inactive nosepokes $\left(F_{(1,12)}=44.19, p<0.05\right)$. Overall, responding decreased across extinction $\left(F_{(1,12)}=15.16, p<0.05\right)$, which was greater for the active than the inactive nosepoke $\left(F_{(1,12)}=18.07, p<0.05\right)$. However, there were no interactions between extinction and any of the differences between groups $\left(F_{(1,12)}=0.22, p>0.05\right)$.

For tests in the extinction (ABB) and training context (ABA) contexts, the hM4Di group responded significantly less than the eYFP group $\left(F_{(1,12)}=9.73, p<0.05\right)($ Fig. $2 B)$. There was also significantly more active than inactive responding $\left(F_{(1,12)}=\right.$ $32.80, p<0.05)$, significantly more responding in the training context $(\mathrm{ABA})$ compared with the extinction context $(\mathrm{ABB})$ $\left(F_{(1,12)}=9.26, p<0.05\right)$, and a context $\times$ manipulanda interaction $\left(F_{(1,12)}=15.64, p<0.05\right)$, providing evidence for contextinduced reinstatement. There was significantly less reinstatement in the hM4Di group because the three-way DREADD $\times$ context $\times$ manipulanda interaction was significant $\left(F_{(1,12)}=6.46\right.$, $p<0.05)$. So, chemogenetic inhibition of VP attenuated contextinduced reinstatement of extinguished alcohol seeking.

Next, animals were tested for reacquisition (Fig. 2B). Overall, there were more active than inactive nosepokes $\left(F_{(1,12)}=50.18\right.$, $p<0.05)$ and an overall significant difference between eYFP and hM4Di groups $\left(F_{(1,12)}=7.89, p<0.05\right)$. There was also a DREADD $\times$ manipulanda interaction $\left(F_{(1,12)}=6.98, p<0.05\right)$ showing that chemogenetic VP inhibition reduced reacquisition.

\section{hm3Dq histology}

Figure $2 A$ shows the extent of eYFP-IR across all rats included in the analyses with each rat represented at $20 \%$ opacity. Three rats were excluded due to expression of the eYFP or hM3Dq being located either unilaterally or regions outside VP.

\section{hM3Dq behavior}

All rats acquired alcohol self-administration. Averaged across the last $3 \mathrm{~d}$ of acquisition training, the mean \pm SEM nosepokes for eYFP were $82.52 \pm 6.12$ (active) and $2.67 \pm 0.80$ (inactive) and for hM3Dq were $93.61 \pm 5.06$ (active) and $2.00 \pm 0.66$ (inactive). There were significantly more active than inactive nosepokes $\left(F_{(1,11)}=394.12, p<0.05\right)$ but no overall difference between eYFP and hM3Dq $\left(F_{(1,11)}<1.31, p>0.05\right)$ groups. During extinction training (Fig. $2 C$, inset), there was no overall difference between groups $\left(F_{(1,11)}<1, p>0.05\right)$. All rats made significantly more active than inactive nosepokes $\left(F_{(1,11)}=59.29, p<0.05\right)$, and this was greater for the hM3Dq compared with the eYFP group $\left(F_{(1,11)}=5.70, p<0.05\right)$. Responding decreased across days of extinction $\left(F_{(1,11)}=28.93, p<0.05\right)$. This decrease was greater for the active nosepoke $\left(F_{(1,11)}=40.25, p<0.05\right)$, and there was a three-way DREADD $\times$ manipulanda $\times$ day interaction $\left(F_{(1,11)}=10.12, p<0.05\right)$. This was unexpected but shows that the decrease in active nosepoke responding during extinction was greater in the eYFP versus hM3Dq group.

For tests in the extinction (ABB) and training contexts (ABA) (Fig. $2 C$ ), there was more responding in the hM3Dq compared with the eYFP group $\left(F_{(1,11)}=6.02, p<0.05\right)$. There was also significantly more active than inactive responding $\left(F_{(1,11)}=\right.$ $46.68, p<0.05)$ that was equivalent across groups $\left(F_{(1,11)}<1\right.$, $p<0.05)$. There was significantly more responding in the training context $(\mathrm{ABA})$ compared with the extinction context $(\mathrm{ABB})$ $\left(F_{(1,11)}=71.66, p<0.05\right)$, and this increase was significantly greater for the hM3Dq compared with the eYFP group $\left(F_{(1,11)}=\right.$ 
A

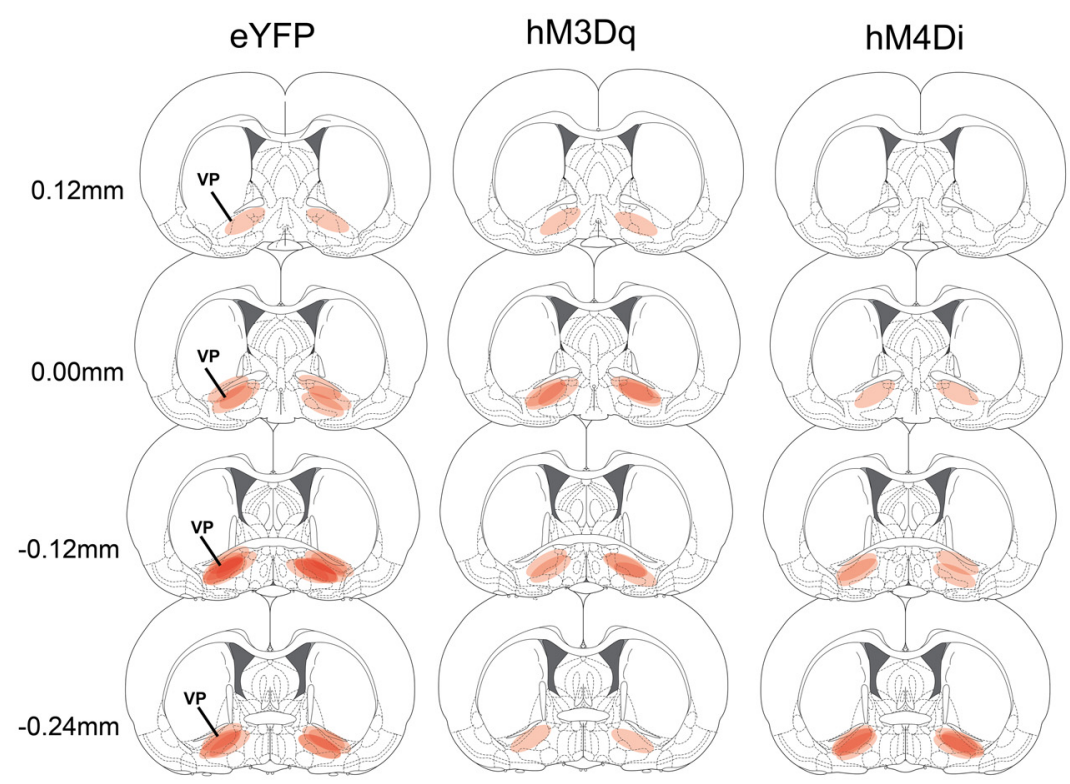

B
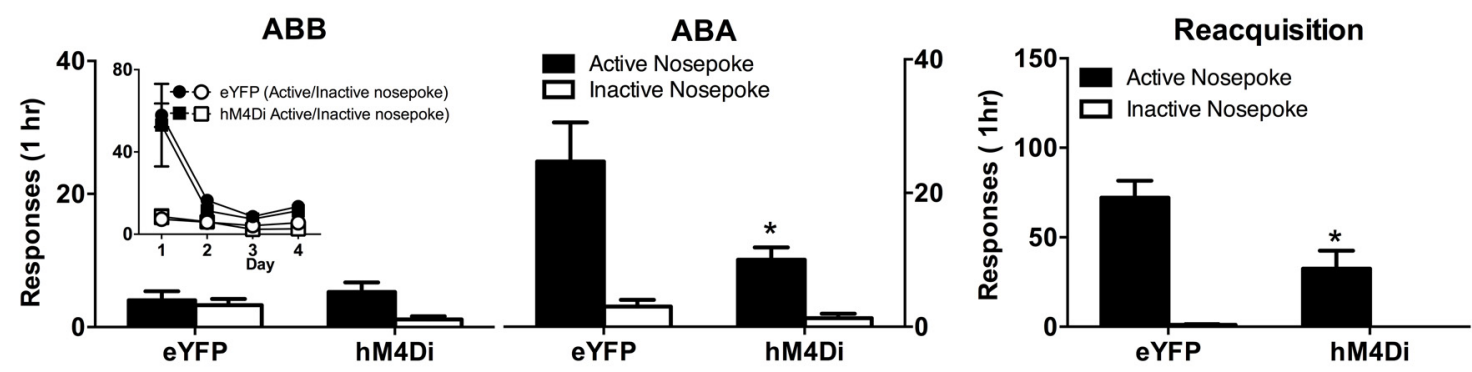

$c$
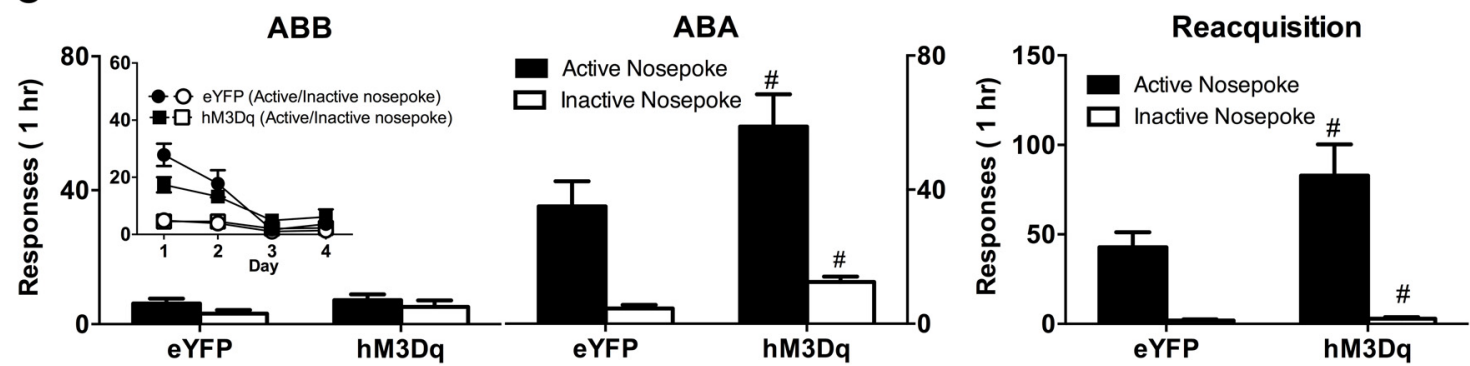

Figure 2. A, Location of eYFP, hM3Dq, and hM4Di expression in VP. B, Mean ( \pm SEM) responding on tests in the extinction (ABB) and training (ABA) contexts as well as during reacquisition for hM4Di $(n=7)$ versus eYFP $(n=7)$ groups. Inset, Responding during extinction training. There was significant context-induced reinstatement that was reduced in the $h M 4 D i$ groups, and this chemogenetic silencing also significantly reduced reacquisition of alcohol seeking. $C$, Mean ( \pm SEM) responding on tests in the extinction (ABB) and training (ABA) contexts as well as during reacquisition for $\mathrm{hM} 3 \mathrm{Dq}(n=6)$ versus eYFP $(n=7)$ groups. Inset, Responding during extinction training. There was significant context-induced reinstatement, but the hM3Dq manipulation nonselectively increased responding during this reinstatement and during reacquisition. ${ }^{*} p<0.05$, significant interaction between context, manipulanda, and DREADD. ${ }^{\#} p<0.05$, significant main effect of DREADD.

$7.41, p<0.05)$. Finally, there was evidence for context-induced reinstatement (i.e., a context $\times$ manipulanda interaction; $\left.F_{(1,11)}=29.67, p<0.05\right)$, but this did not interact with the DREADD manipulation $\left(F_{(1,11)}=1.64, p>0.05\right)$. So, chemogenetic VP excitation increased responding during reinstatement, but it acted nonselectively during this test on both active and inactive nosepokes.

During reacquisition (Fig. 2C), VP chemogenetic excitation again increased responding $\left(F_{(1,11)}=4.99, p<0.05\right)$, and there were significantly more active than inactive nosepokes $\left(F_{(1,11)}=\right.$ $42.68, p<0.05)$. However, this chemogenetic increase in responding was again relatively nonselective because it did not dif- fer between the active and inactive nosepokes $\left(F_{(1,11)}=4.43, p>\right.$ 0.05).

These effects of the hM3Dq manipulation are worth addressing. Whereas the impact of VP silencing via the hM4Di was selective to the active nosepoke, the impact of VP excitation via the hM3Dq was not. Rather, VP excitation via the hM3Dq increased responding on both the active and inactive nosepoke. This could reflect a chemogenetic amplification of general arousal or appetitive motivation, or it could reflect chemogenetic increases in locomotor activity. Regardless, it suggests caution in interpreting the effects of the hM3Dq and highlights the utility of the control manipulanda in this experiment. 
Experiment 3: chemogenetic disconnection of the VP $\rightarrow$ VTA and VP $\rightarrow$ STN pathways on context-induced reinstatement and reacquisition of alcohol seeking

Having established that the VP $\rightarrow$ VTA and VP $\rightarrow$ STN pathways are both recruited during reinstatement and that chemogenetic silencing of VP attenuates both context-induced reinstatement and reacquisition of alcohol seeking, we next asked whether the $\mathrm{VP} \rightarrow$ VTA and VP $\rightarrow$ STN pathways contribute to reinstatement. To do so, we used a chemogenetic disconnection strategy. We expressed the inhibitory hM4Di in one VP and the contralateral VTA (VP $\rightarrow$ VTA) or in one VP and the contralateral STN $(\mathrm{VP} \rightarrow \mathrm{STN})$. For our control group, we expressed the hM4Di in one VP and ipsilateral VTA or ipsilateral STN (ipsilateral). We trained the rats and then extinguished their lever responding, then tested for expression of extinction $(\mathrm{ABB})$, context-induced reinstatement $(\mathrm{ABA})$, and for reacquisition of alcohol-seeking.

We also assessed the effects of VP $\rightarrow$ VTA and VP $\rightarrow$ STN disconnection on motivation to respond for alcoholic beer on a PR schedule because deep brain stimulation in STN reduces motivation to work for cocaine and alcohol (Baunez et al., 2005; Rouaud et al., 2010), and we wanted to determine whether this depended on VP-STN interactions. Finally, we assessed the impact of VP $\rightarrow$ VTA and VP $\rightarrow$ STN disconnection on locomotor activity.

\section{Histology}

Four rats were excluded due to hM4Di misplaced (2 STN and 2 VTA misplacements). Figure $3 A$ shows the extent of eYFP-IR across all rats included in the analyses with each rat represented at $20 \%$ opacity.

\section{Behavior}

All rats acquired self-administration. Averaged across the last $3 \mathrm{~d}$ of acquisition training, the mean \pm SEM nosepokes for ipsilateral were $98.53 \pm 9.00$ (active) and $2.03 \pm 0.55$ (inactive), $\mathrm{VP} \rightarrow \mathrm{STN}$ were $72.75 \pm 4.90$ (active) and $1.42 \pm 0.25$ (inactive), and VP $\rightarrow$ VTA were $100.54 \pm 10.90$ (active) $0.79 \pm 0.21$ (inactive). There were significantly more active than inactive nosepokes $\left(F_{(1,25)}=\right.$ $279.25, p<0.05)$ but no overall difference between ipsilateral disconnection compared with VP $\rightarrow$ STN and VP $\rightarrow$ VTA disconnection $\left(F_{(1,25)}=1.39, p>0.05\right)$ groups or between $\mathrm{VP} \rightarrow$ $\mathrm{STN}$ and VP $\rightarrow$ VTA disconnection $\left(F_{(1,25)}=3.68, p>0.05\right)$.

During extinction training (Fig. $3 B$, inset), rats made significantly more active than inactive nosepokes $\left(F_{(1,25)}=94.74, p<\right.$ $0.05)$. Overall, responding decreased across days of extinction $\left(F_{(1,25)}=28.08, p<0.05\right)$. This decrease was greater for the active than the inactive nosepoke $\left(F_{(1,25)}=43.62, p<0.05\right)$. There were no differences between groups during extinction $\left(F_{(1,25)}<1, p>\right.$ $0.05)$. Figure $3 B$ shows the mean \pm SEM responses during tests in the extinction context $(\mathrm{ABB})$ and the training context $(\mathrm{ABA})$. There was an overall main effect of contralateral disconnection (ipsilateral vs VP $\rightarrow$ STN and VP $\rightarrow$ VTA; $F_{(1,25)}=14.96, p<$ $0.05)$ but no difference between the VP $\rightarrow$ STN and VP $\rightarrow$ VTA disconnection groups. Overall, there was more active than inactive responding $\left(F_{(1,25)}=102.43, p<0.05\right)$, and this was greater for ipsilateral versus VP $\rightarrow$ STN and VP $\rightarrow$ VTA disconnection groups $\left(F_{(1,25)}=9.72, p<0.05\right)$, which did not differ $\left(F_{(1,25)}<1\right.$, $p>0.05)$. There was evidence for context-induced reinstatement because there was significantly more responding in the training context (ABA) compared with the extinction context (ABB) $\left(F_{(1,25)}=17.22, p<0.05\right)$, which was greater for the active compared with the inactive nosepoke $\left(F_{(1,25)}=38.73, p<0.05\right)$. Importantly, this was significantly reduced among the $\mathrm{VP} \rightarrow \mathrm{STN}$ and VP $\rightarrow$ VTA disconnection groups (three-way interaction: $\left.F_{(1,25)}=10.80, p<0.05\right)$. However, the VP $\rightarrow$ STN and VP $\rightarrow$ VTA disconnection groups did not differ from each other $\left(F_{(1,25)}\right.$ $<1, p>0.05)$. So, chemogenetic disconnection of either $\mathrm{VP} \rightarrow$ STN and VP $\rightarrow$ VTA pathways reduced context-induced reinstatement.

Next, we tested rats for reacquisition (Fig. 3B). During this test, there were significantly more active than inactive nosepokes $\left(F_{(1,25)}=88.75, p<0.05\right)$. There was an overall effect of disconnection (ipsilateral vs VP $\rightarrow \mathrm{STN}$ and VP $\rightarrow \mathrm{VTA})\left(F_{(1,25)}=4.90\right.$, $p<0.05$ ) and also a disconnection (ipsilateral vs VP $\rightarrow$ STN and $\mathrm{VP} \rightarrow \mathrm{VTA}) \times$ manipulanda interaction $\left(F_{(1,25)}=4.34, p<\right.$ $0.05)$. However, there was no overall difference between the VP $\rightarrow$ STN and VP $\rightarrow$ VTA disconnection groups $\left(F_{(1,25)}<1, p>\right.$ $0.05)$ or an interaction with manipulanda $\left(F_{(1,25)}<1, p>0.05\right)$. So, chemogenetic disconnection of the VP $\rightarrow$ STN and VP $\rightarrow$ VTA pathways reduced reacquisition.

We then gave all animals a reminder self-administration session to ensure that responding was equivalent. Responding on the active nosepoke was high during this session (ipsilateral mean $=127.4 ; \mathrm{SEM}=16.9 ; \mathrm{VP} \rightarrow$ VTA mean $=115.2, \mathrm{SEM}=$ 9.5; VP $\rightarrow$ STN mean $=134.0$, SEM $=13.6)$, inactive nosepokes were low (mean $<3$ for each group), and there were no differences between groups $\left(F_{(1,25)}<1, p>0.05\right)$. The following day, we tested animals for motivation to respond for and consume alcoholic beer via a PR test (Fig. 3C).

Overall, the disconnection groups (VP $\rightarrow$ STN and VP $\rightarrow$ VTA) made significantly fewer responses than the ipsilateral group during PR test $\left(F_{(1,25)}=10.78, p<0.05\right)$, and this decrease was greater on the active than inactive nosepoke $\left(F_{(1,25)}=9.64\right.$, $p<0.05)$. So, disconnecting the VP $\rightarrow$ STN and VP $\rightarrow$ VTA pathways reduced responding. But, again, there were no differences between the VP $\rightarrow$ STN and VP $\rightarrow$ VTA disconnections $\left(F_{(1,25)}<1, p>0.05\right)$. The reduction in responding caused by disconnecting the VP $\rightarrow$ STN and VP $\rightarrow$ VTA pathways was associated with a commensurate reduction in breakpoints (last ratio completed) (Fig. 3C) with the VP $\rightarrow$ STN and VP $\rightarrow$ VTA groups significantly lower than the ipsilateral control $\left(F_{(1,25)}=\right.$ $12.77, p<0.05)$, and the $\mathrm{VP} \rightarrow \mathrm{STN}$ and $\mathrm{VP} \rightarrow \mathrm{VTA}$ groups did not differ $\left(F_{(1,25)}<1, p>0.05\right)$. Finally, we tested the groups for locomotor activity in a novel environment (Fig. $3 C$ ). There was no effect of disconnection (ipsilateral vs VP $\rightarrow$ STN and VP $\rightarrow$ VTA; $\left.F_{(1,25)}<1, p>0.05\right)$ and no difference between the VP $\rightarrow$ $\mathrm{STN}$ and VP $\rightarrow$ VTA groups $\left(F_{(1,25)}<1, p>0.05\right)$ for locomotor activity. So, chemogenetic disconnection of either the VP $\rightarrow$ VTA or VP $\rightarrow$ STN pathways reduces context-induced reinstatement and reacquisition of alcoholic beer seeking, reduces motivation to respond for alcoholic beer on a PR schedule, but does not disrupt locomotor activity.

\section{Discussion}

We examined the role of VP, and its projections to the VTA and $\mathrm{STN}$, in context-induced reinstatement and reacquisition of alcohol seeking. Consistent with our previous findings, we showed that return to the training context after extinction in a second different context was able to reinstate extinguished alcohol seeking and that this reinstatement was associated with significant recruitment of VP neurons, as shown by expression of the c-Fos protein (Perry and McNally, 2013). Using dual-retrograde tracing, we mapped some of the VP output pathways recruited during context-induced reinstatement and showed a significant recruitment of both the VP $\rightarrow$ VTA and the VP $\rightarrow$ STN pathways during this reinstatement. We were able to confirm that these 
A

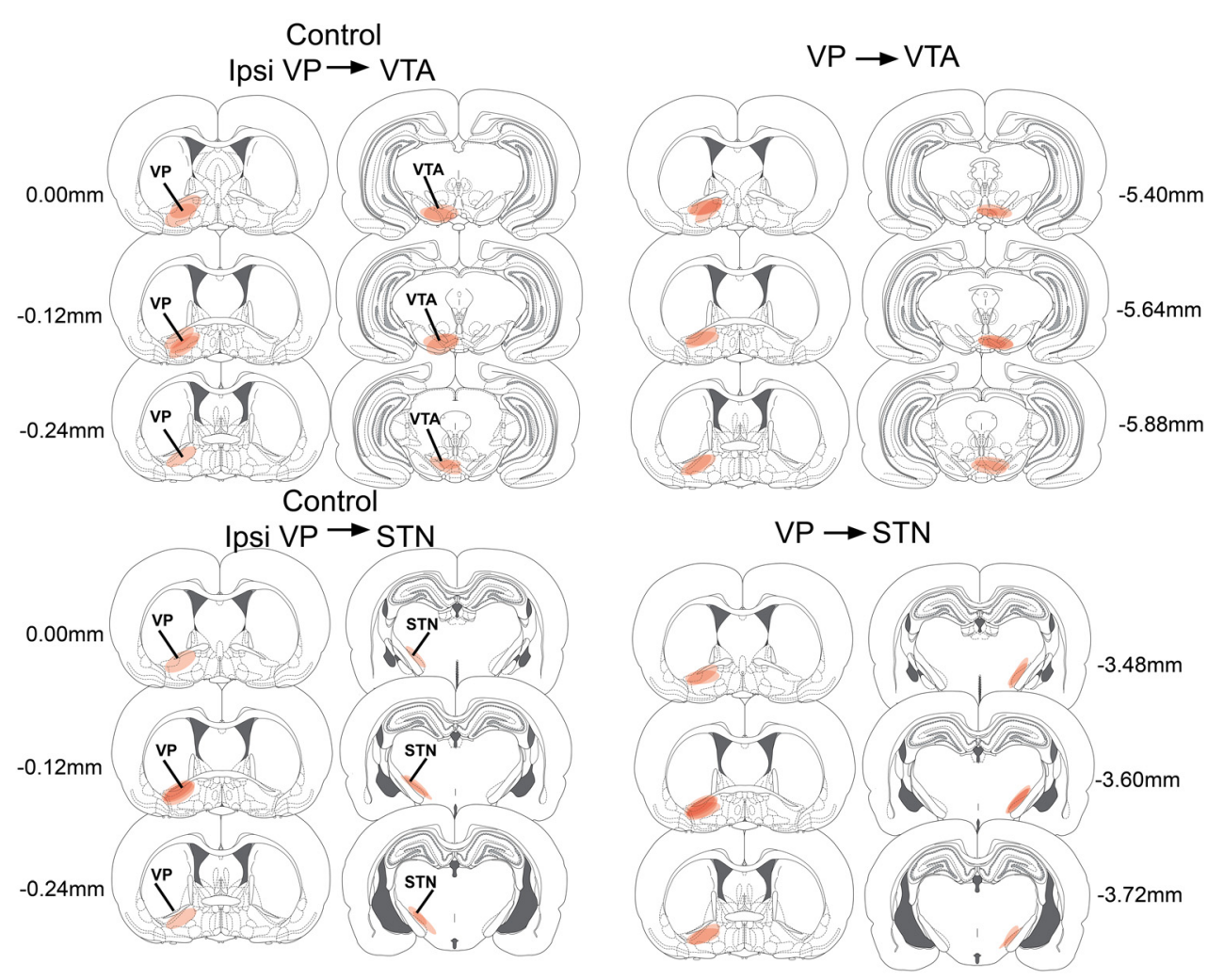

B

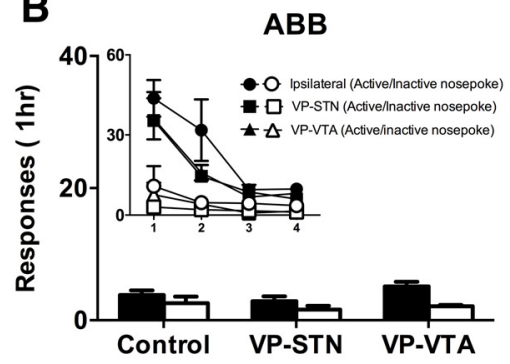

C

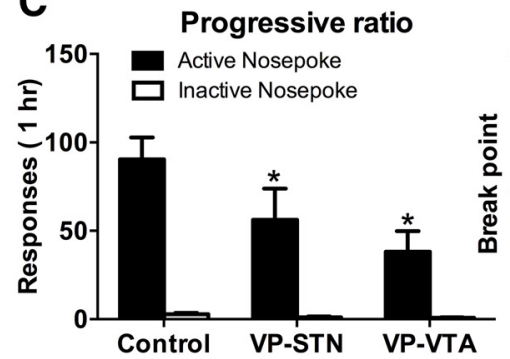

ABA

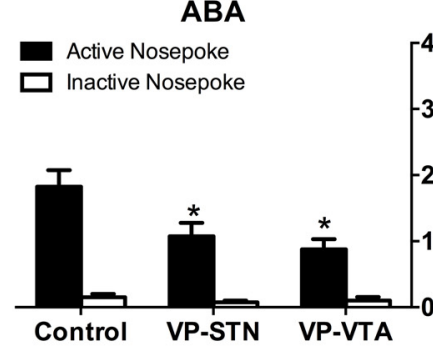

Progressive ratio

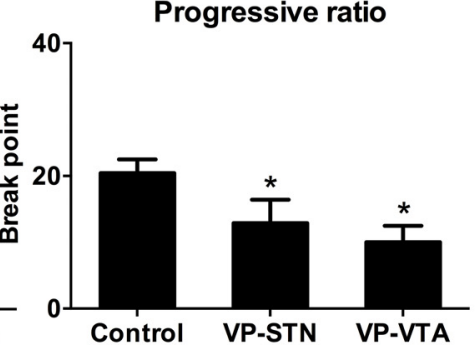

Reacquisition

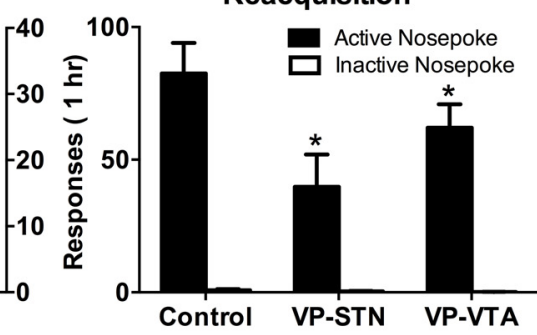

Locomotor

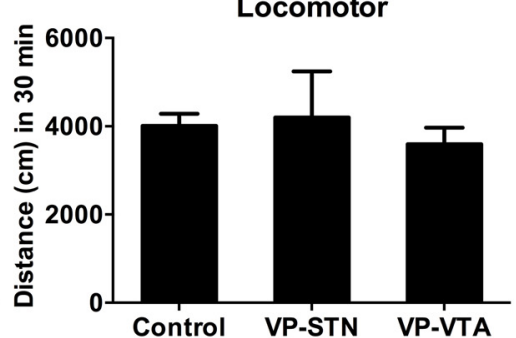

Figure 3. $\boldsymbol{A}$, Location of hM4Di expression in VP, VTA, and STN for groups Control $(n=12), \mathrm{VP} \rightarrow \mathrm{VTA}(n=8)$, and VP $\rightarrow$ STN $(n=8)$. $\boldsymbol{B}$, Mean $( \pm$ SEM) responding on tests in the extinction $(A B B)$ and training $(A B A)$ contexts as well as during reacquisition. Inset, Responding during extinction training. There was significant context-induced reinstatement that was reduced in the VP $\rightarrow$ VTA and VP $\rightarrow$ STN disconnection groups, and this chemogenetic silencing also significantly reduced reacquisition of alcohol seeking. $\boldsymbol{C}$, Mean ( \pm SEM) responding on tests for PR and locomotor activity. Chemogenetic disconnection in the VP $\rightarrow$ VTA and VP $\rightarrow$ STN groups reduced responding and breakpoints but did not affect locomotor activity. ${ }^{*} p<0.05$, significant difference between VP $\rightarrow$ VTA and VP $\rightarrow$ STN versus Control.

were distinct VP output pathways with few VP neurons projecting to both VTA and STN. Our findings on recruitment of the $\mathrm{VP} \rightarrow$ VTA pathway during context-induced reinstatement extend previous reports of recruitment of this pathway during cueinduced reinstatement of cocaine seeking (Mahler and AstonJones, 2012). Importantly, we show that this recruitment is not unique. It is shared with another major VP output pathway, the $\mathrm{VP} \rightarrow$ STN projection.
Multiple VP output pathways and reinstatement

Using a chemogenetic disconnection strategy, we then showed that both the VP $\rightarrow$ VTA and the VP $\rightarrow$ STN pathways were necessary for context-induced reinstatement and reacquisition of alcohol seeking because chemogenetic disconnection of either pathway was sufficient to attenuate reinstatement compared with ipsilateral disconnection. Interestingly, this role for VP $\rightarrow$ VTA and the $\mathrm{VP} \rightarrow$ STN pathways extended to motivation to respond 
for and consume alcoholic beer under a PR schedule, showing overlap in the neural substrates for reinstatement and selfadministration at the level of VP and its major output pathways. Finally, despite the well-documented role of VP in locomotor activity (Root et al., 2015), there was no evidence here for alterations in activity following chemogenetic disconnection of the $\mathrm{VP} \rightarrow \mathrm{VTA}$ and the VP $\rightarrow$ STN pathways, although it remains possible that nonspecific effects, such as increased locomotor activity, did contribute to the impact of chemogenetic excitation of VP itself. Together, these experiments provide converging lines of evidence for the contribution of multiple VP output pathways to context-induced reinstatement and reacquisition of alcohol seeking.

Multiple VP inputs are recruited during context-induced reinstatement of alcohol-seeking (Perry and McNally, 2013) and context-induced reinstatement and reacquisition depend on different VP input pathways (Khoo et al., 2015). However, our first finding is that common and multiple VP output pathways contribute to context-induced reinstatement and reacquisition of alcohol seeking. These roles for VP $\rightarrow$ STN and VP $\rightarrow$ STN pathways in multiple forms of reinstatement to alcohol seeking are consistent with the view that different pallidal channels control complementary aspects of motivated behavior (Root et al., 2015). VP neurons projecting to the STN are located predominantly in dorsolateral VP (VPdl) and receive extensive inputs from AcbC (Zahm et al., 1987, 1996; Groenewegen et al., 1993; Tripathi et al., 2013). This input is not necessary for context-induced reinstatement (Khoo et al., 2015) but is necessary for reacquisition of alcohol seeking (Khoo et al., 2015) as well as cue and primed reinstatement of cocaine seeking (Stefanik et al., 2013). In contrast, VP neurons projecting to the VTA are located predominantly in VPvm and receive extensive inputs from accumbens shell (AcbSh) (Groenewegen et al., 1993; Zahm et al., 1996; Tripathi et al., 2010), a structure critical for context-induced reinstatement to seeking a variety of drugs of abuse (Bossert et al., 2006, 2007; Hamlin et al., 2006, 2007; Fuchs et al., 2008; Chaudhri et al., 2009; Marchant et al., 2009; Millan and McNally, 2012). The role of the AcbSh $\rightarrow$ VP pathway in context-induced reinstatement remains to be determined. Nevertheless, one attractive possibility supported by our data is that inputs from corticostriatal and amygdalostriatal circuits interface with segregated pallidal outputs, encompassing VPvm $\rightarrow$ lateral hypothalamus/VTA and VPdl $\rightarrow$ STN/substantia nigra (Zahm and Heimer, 1990; Groenewegen et al., 1993), to mediate reinstatement to drug seeking (Fig. 4).

Our second key finding is that the role of STN in reinstatement as well as alcohol seeking more generally depends, at least in part, on VP inputs. STN is gaining increased attention for its role in appetitive motivation and drug seeking (Uslaner et al., 2008; Baunez et al., 2011). STN manipulations reduce motivation for cocaine as well as alcohol (Baunez et al., 2005; Lardeux and Baunez, 2008; Rouaud et al., 2010) and reduce reinstatement of methamphetamine seeking (Baracz et al., 2015). Based on these findings, STN has been identified as a target for deep brain stimulation treatment of addiction (Baunez et al., 2011; Pelloux and Baunez, 2013) and related disorders of motivation (Bandini et al., 2007). However, the circuit level mechanisms for STN contributions to reinstatement, and appetitive motivation more generally, are poorly understood. Here we show that this role for STN depends substantially on inputs from VP. Chemogenetic disconnection of the VP $\rightarrow$ STN pathway not only reduced contextinduced reinstatement and reacquisition but also significantly reduced motivation to respond in a PR task, showing overlap in

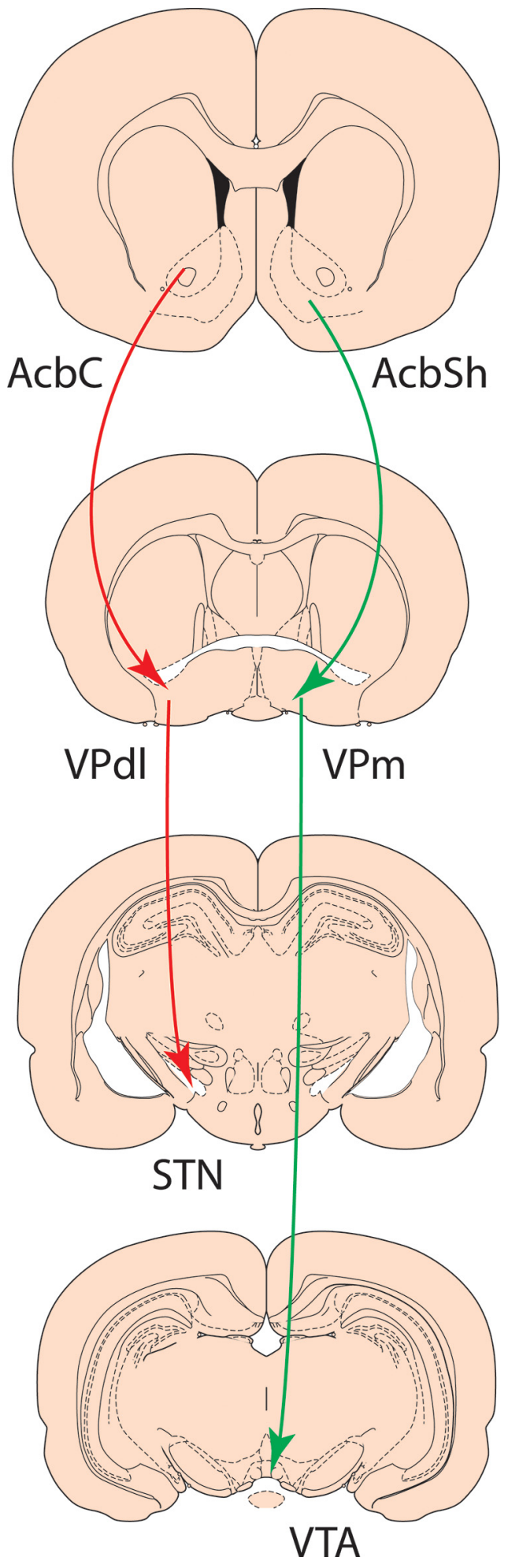

Figure 4. Organization of segregated pallidal channels, encompassing medial VP $(\mathrm{VPm}) \rightarrow$ VTA and VPdl $\rightarrow$ STN, that interface with distinct ventral striatal, cortical, and amygdala inputs to mediate reinstatement of drug seeking.

the neural substrates for reinstatement and self-administration at the level of the VP $\rightarrow$ STN pathway. Importantly, there was no evidence here for a general suppressive effect of this chemogenetic disconnection on locomotor activity. There is extensive reciprocal connectivity between VPdl and STN (Zahm et al., 1987; Zahm and Heimer, 1990), and the role of STN $\rightarrow$ VP projections 
in reinstatement remain to be determined, but our retrograde tracing data combined with chemogenetic disconnection provides strong evidence that STN contributions to reinstatement and motivation depend on VP inputs.

\section{Further issues}

Our findings leave several questions unanswered. First, it is not clear why these distinct VP output pathways contribute to both these forms of reinstatement. One possibility is that these pathways control distinct aspects of reinstatement behavior that our measures simply could not isolate. For example, consistent with recent distinctions between AcbC and AcbSh (Floresco, 2015), the VP $\rightarrow$ STN pathway may control approach, whereas the VP $\rightarrow$ VTA pathway may maintain task-related performance to ensure sustained responding in the reinstatement tasks (Floresco, 2015; Root et al., 2015). Reinstatement is likely assembled from these (and other) different functions, and their disruption would be sufficient to reduce context-induced reinstatement or reacquisition when measured via total responses, but our measures may lack the resolution to separately isolate these functions. Second, it is unclear to what extent the roles for these VP output pathways in reinstatement are specific to seeking drug rewards versus appetitive motivation more generally. The VP $\rightarrow$ VTA pathway has been implicated more broadly in the control over actions by environmental stimuli (Leung and Balleine, 2013), so it likely serves a general role across different natural and drug rewards. Our findings that chemogenetic silencing disrupted responding in the presence (reacquisition) or absence (renewal) of alcohol and also reduced motivation on a PR schedule support this possibility. Similarly, although the STN was initially identified as serving opposing roles in the motivation for cocaine versus natural rewards (Baunez et al., 2005), more recent work shows that STN contributions are linked to initial preference for reward rather than whether it is a natural or drug reward (Lardeux and Baunez, 2008). Finally, VP output pathways converge directly, or indirectly, on VTA and SNr, but the nature of VTA and SNr contributions to context-induced reinstatement and reacquisition remains poorly understood. Although VTA contributes to context-induced reinstatement of heroin seeking (Bossert et al., 2004), its role in context-induced reinstatement to seeking other drugs is unknown. Moreover, the critical VTA neuronal populations mediating context-induced reinstatement and reacquisition are unknown. VP inputs provide GABAergic control over VTA dopamine neuron activity and dopamine efflux in ventral striatum (Floresco et al., 2003; Grace et al., 2007; Grace, 2016). Mahler et al. (2014) showed that VTA TH neurons were necessary for cue-induced reinstatement of cocaine seeking but that this was not due to direct input from VP terminals, raising the possibility that complex disinhibitory intra-VTA circuits contribute to reinstatement.

In conclusion, here we show that multiple VP output pathways contribute to reinstatement of alcohol seeking. Much remains to be learned approximately how VP contributes to reinstatement of drug seeking. Most research has focused on roles of striatal inputs (McFarland and Kalivas, 2001; Torregrossa and Kalivas, 2008; Leung and Balleine, 2013; Stefanik et al., 2013; Khoo et al., 2015). However, the convergence of multiple activated striatal, thalamic, and amygdala inputs in VP (Perry and McNally, 2013) with recruitment of multiple VP output pathways during reinstatement, combined with recent findings on the timing of reward related VP neuron activity (Richard et al., 2016), suggests that the role for VP in reinstatement of drug seeking is likely to be more complex than currently appreciated.

\section{References}

Bandini F, Primavera A, Pizzorno M, Cocito L (2007) Using STN DBS and medication reduction as a strategy to treat pathological gambling in Parkinson's disease. Parkinsonism Relat Disord 13:369-371. CrossRef Medline

Baracz SJ, Everett NA, Cornish JL (2015) The involvement of oxytocin in the subthalamic nucleus on relapse to methamphetamine-seeking behaviour. PLoS One 10:e0136132. CrossRef Medline

Baunez C, Dias C, Cador M, Amalric M (2005) The subthalamic nucleus exerts opposite control on cocaine and "natural" rewards. Nat Neurosci 8:484-489. CrossRef Medline

Baunez C, Yelnik J, Mallet L (2011) Six questions on the subthalamic nucleus: lessons from animal models and from stimulated patients. Neuroscience 198:193-204. CrossRef Medline

Boik RJ (2016) A priori tests in repeated measures designs: effects of nonsphericity. Psychometrika 46:241-255.

Bossert JM, Liu SY, Lu L, Shaham Y (2004) A role of ventral tegmental area glutamate in contextual cue-induced relapse to heroin seeking. J Neurosci 24:10726-10730. CrossRef Medline

Bossert JM, Gray SM, Lu L, Shaham Y (2006) Activation of group II metabotropic glutamate receptors in the nucleus accumbens shell attenuates context-induced relapse to heroin seeking. Neuropsychopharmacology 31:2197-2209. CrossRef Medline

Bossert JM, Poles GC, Wihbey KA, Koya E, Shaham Y (2007) Differential effects of blockade of dopamine D1-family receptors in nucleus accumbens core or shell on reinstatement of heroin seeking induced by contextual and discrete cues. J Neurosci 27:12655-12663. CrossRef Medline

Bouton ME, Todd TP (2014) A fundamental role for context in instrumental learning and extinction. Behav Processes 104:13-19. CrossRef Medline

Chaudhri N, Sahuque LL, Janak PH (2009) Ethanol seeking triggered by environmental context is attenuated by blocking dopamine D1 receptors in the nucleus accumbens core and shell in rats. Psychopharmacology 207:303-314. CrossRef Medline

Crombag HS, Shaham Y (2002) Renewal of drug seeking by contextual cues after prolonged extinction in rats. Behav Neurosci 116:169-173. CrossRef Medline

Floresco SB (2015) The nucleus accumbens: an interface between cognition, emotion, and action. Annu Rev Psychol 66:25-52. CrossRef Medline

Floresco SB, West AR, Ash B, Moore H, Grace AA (2003) Afferent modulation of dopamine neuron firing differentially regulates tonic and phasic dopamine transmission. Nat Neurosci 6:968-973. CrossRef Medline

Fuchs RA, Ramirez DR, Bell GH (2008) Nucleus accumbens shell and core involvement in drug context-induced reinstatement of cocaine seeking in rats. Psychopharmacology 200:545-556. CrossRef Medline

Grace AA (2016) Dysregulation of the dopamine system in the pathophysiology of schizophrenia and depression. Nat Rev Neurosci 17:524-532. CrossRef Medline

Grace AA, Floresco SB, Goto Y, Lodge DJ (2007) Regulation of firing of dopaminergic neurons and control of goal-directed behaviors. Trends Neurosci 30:220-227. CrossRef Medline

Groenewegen HJ, Berendse HW, Haber SN (1993) Organisation of the output of the ventral striatopallidal system in the rat: ventral pallidal efferents. Neuroscience 57:113-142. CrossRef Medline

Hamlin AS, Blatchford KE, McNally GP (2006) Renewal of an extinguished instrumental response: neural correlates and the role of D1 dopamine receptors. Neuroscience 143:25-38. CrossRef Medline

Hamlin AS, Newby J, McNally GP (2007) The neural correlates and role of D1 dopamine receptors in renewal of extinguished alcohol-seeking. Neuroscience 146:525-536. CrossRef Medline

Hamlin AS, Clemens KJ, McNally GP (2008) Renewal of extinguished cocaine-seeking. Neuroscience 151:659-670. CrossRef Medline

Harris RJ (2004) ANOVA: an analysis of variance primer. Itasca, IL: F.E. Peacock.

Heimer L, Switzer RD, Van Hoesen GW (1982) Ventral striatum and ventral pallidum: components of the motor system? Trends Neurosci 42:83-87.

Kalivas PW, Volkow ND (2005) The neural basis of addiction: a pathology of motivation and choice. Am J Psychiatry 162:1403-1413. CrossRef Medline

Kalivas PW, Volkow ND (2011) New medications for drug addiction hiding in glutamatergic neuroplasticity. Mol Psychiatry 16:974-986. CrossRef Medline 
Khoo AT, Gibson GD, Prasad AA, McNally GP (2015) Role of the striatopallidal pathway in renewal and reacquisition of alcohol seeking. Behav Neurosci 129:2-7. CrossRef Medline

Lardeux S, Baunez C (2008) Alcohol preference influences the subthalamic nucleus control on motivation for alcohol in rats. Neuropsychopharmacology 33:634-642. CrossRef Medline

Leung BK, Balleine BW (2013) The ventral striato-pallidal pathway mediates the effect of predictive learning on choice between goal-directed actions. J Neurosci 33:13848-13860. CrossRef Medline

Mahler SV, Aston-Jones GS (2012) Fos activation of selective afferents to ventral tegmental area during cue-induced reinstatement of cocaine seeking in rats. J Neurosci 32:13309-13326. CrossRef Medline

Mahler SV, Vazey EM, Beckley JT, Keistler CR, McGlinchey EM, Kaufling J, Wilson SP, Deisseroth K, Woodward JJ, Aston-Jones G (2014) Designer receptors show role for ventral pallidum input to ventral tegmental area in cocaine seeking. Nat Neurosci 17:577-585. CrossRef Medline

Marchant NJ, Hamlin AS, McNally GP (2009) Lateral hypothalamus is required for context-induced reinstatement of extinguished reward seeking. J Neurosci 29:1331-1342. CrossRef Medline

Marchant NJ, Millan EZ, McNally GP (2012) The hypothalamus and the neurobiology of drug seeking. Cell Mol Life Sci 69:581-597. CrossRef Medline

Marchant NJ, Rabei R, Kaganovsky K, Caprioli D, Bossert JM, Bonci A, Shaham Y (2014) A critical role of lateral hypothalamus in context-induced relapse to alcohol seeking after punishment-imposed abstinence. J Neurosci 34:7447-7457. CrossRef Medline

McFarland K, Kalivas PW (2001) The circuitry mediating cocaine-induced reinstatement of drug-seeking behavior. J Neurosci 21:8655-8663. Medline

McFarland K, Davidge SB,Lapish CC, Kalivas PW (2004) Limbic and motor circuitry underlying footshock-induced reinstatement of cocaine-seeking behavior. J Neurosci 24:1551-1560. CrossRef Medline

Millan EZ, McNally GP (2012) Cocaine- and amphetamine-regulated transcript in the nucleus accumbens shell attenuates context-induced reinstatement of alcohol seeking. Behav Neurosci 126:690-698. CrossRef Medline

Paxinos G, Watson C (2007) The rat brain in stereotaxic coordinates, Ed 6. Amsterdam: Elsevier.

Pelloux Y, Baunez C (2013) Deep brain stimulation for addiction: why the subthalamic nucleus should be favored. Curr Opin Neurobiol 23:713720. CrossRef Medline

Perry CJ, McNally GP (2013) A role for the ventral pallidum in contextinduced and primed reinstatement of alcohol seeking. Eur J Neurosci 38:2762-2773. CrossRef Medline

Richard JM, Ambroggi F, Janak PH, Fields HL (2016) Ventral pallidum neurons encode incentive value and promote cue-elicited instrumental actions. Neuron 90:1165-1173. CrossRef Medline

Richardson NR, Roberts DC (1996) Progressive ratio schedules in drug selfadministration studies in rats: a method to evaluate reinforcing efficacy. J Neurosci Methods 66:1-11. CrossRef Medline

Root DH, Melendez RI, Zaborszky L, Napier TC (2015) The ventral pallidum: subregion-specific functional anatomy and roles in motivated behaviors. Prog Neurobiol 130:29-70. CrossRef Medline
Roth BL (2016) DREADDs for neuroscientists. Neuron 89:683-694. CrossRef Medline

Rouaud T, Lardeux S, Panayotis N, Paleressompoulle D, Cador M, Baunez C (2010) Reducing the desire for cocaine with subthalamic nucleus deep brain stimulation. Proc Natl Acad Sci U S A 107:1196-1200. CrossRef Medline

Sengupta A, Winters B, Bagley EE, McNally GP (2016) Disrupted prediction error links excessive amygdala activation to excessive fear. J Neurosci 36:385-395. CrossRef Medline

Smith KS, Tindell AJ, Aldridge JW, Berridge KC (2009) Ventral pallidum roles in reward and motivation. Behav Brain Res 196:155-167. CrossRef Medline

Stefanik MT, Kupchik YM, Brown RM, Kalivas PW (2013) Optogenetic evidence that pallidal projections, not nigral projections, from the nucleus accumbens core are necessary for reinstating cocaine seeking. J Neurosci 33:13654-13662. CrossRef Medline

Tang XC, McFarland K, Cagle S, Kalivas PW (2005) Cocaine-induced reinstatement requires endogenous stimulation of mu-opioid receptors in the ventral pallidum. J Neurosci 25:4512-4520. CrossRef Medline

Torregrossa MM, Kalivas PW (2008) Neurotensin in the ventral pallidum increases extracellular-aminobutyric acid and differentially affects cueand cocaine-primed reinstatement. J Pharmacol Exp Ther 325:556-566. CrossRef Medline

Tripathi A, Prensa L, Cebrián C, Mengual E (2010) Axonal branching patterns of nucleus accumbens neurons in the rat. J Comp Neurol 518:46494673. CrossRef Medline

Tripathi A, Prensa L, Mengual E (2013) Axonal branching patterns of ventral pallidal neurons in the rat. Brain Struct Funct 218:1133-1157. CrossRef Medline

Urban DJ, Roth BL (2015) DREADDs (designer receptors exclusively activated by designer drugs): chemogenetic tools with therapeutic utility. Annu Rev Pharmacol Toxicol 55:399-417. CrossRef Medline

Uslaner JM, Dell'Orco JM, Pevzner A, Robinson TE (2008) The influence of subthalamic nucleus lesions on sign-tracking to stimuli paired with food and drug rewards: facilitation of incentive salience attribution? Neuropsychopharmacology 33:2352-2361. CrossRef Medline

Yau JO, McNally GP (2015) Pharmacogenetic excitation of dorsomedial prefrontal cortex restores fear prediction error. J Neurosci 35:74-83. CrossRef Medline

Zahm DS (1989) The ventral striatopallidal parts of the basal ganglia in the rat: II. Compartmentalisation of ventral pallidal efferents. Neuroscience 30:33-50. CrossRef Medline

Zahm DS, Heimer L (1990) Two transpallidal pathways originating in the rat nucleus accumbens. J Comp Neurol 302:437-446. CrossRef Medline

Zahm DS, Zaborszky L, Alheid GF, Heimer L (1987) The ventral striatopallidothalamic projection: II. The ventral pallidothalamic link. J Comp Neurol 255:592-605. CrossRef Medline

Zahm DS, Williams E, Wohltmann C (1996) Ventral striatopallidothalamic projection: IV. Relative involvements of neurochemically distinct subterritories in the ventral pallidum and adjacent parts of the rostroventral forebrain. J Comp Neurol 364:340-362. CrossRef Medline 